\title{
NOTE SUL SUFISMO VISIVO: RAPPRESENTAZIONI GRAFICHE A SUPPORTO DELLA REALIZZAZIONE SPIRITUALE NEL TAṢAWWUF
}

Giovanni Maria Martini (Università di Napoli l'Orientale)

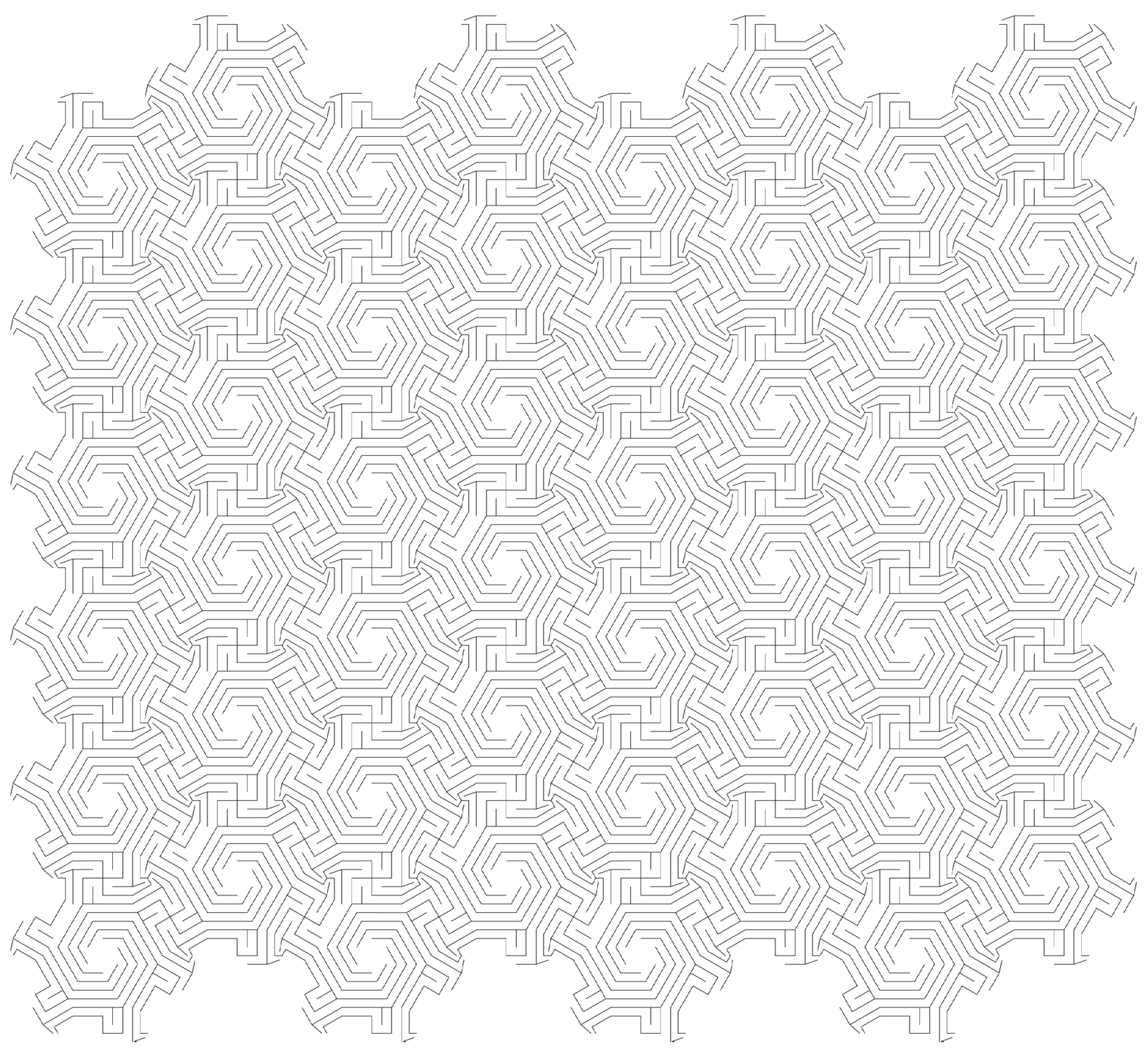


Riassunto: Questo articolo raccoglie considerazioni di carattere introduttivo sul Sufismo visivo, ovvero sul vasto e complesso tema dell'utilizzo di rappresentazioni grafiche nella letteratura sufi, soffermandosi su un aspetto in particolare, ovvero su come questi diagrammi in molti casi siano stati concepiti dai maestri sufi che li idearono e dai loro fruitori come strumenti grafici a supporto della realizzazione spirituale; contemporaneamente esso si interroga, attraverso l'analisi dei testi, sulle ragioni che spinsero alcuni esponenti del Sufismo ad adottare questo particolare mezzo espressivo. Per far ciò sono stati presi in considerazione autori di epoche diverse, partendo da al-Hallăğ (m. 309/922), passando per Ibn 'Arabī (m. 638/1240) -il cui impulso appare determinante nello sviluppo di questo fenómenoproseguendo con alcuni eminenti esponenti della Scuola Akbariana quali Ḥaydar Āmulī (m. dopo il 787/1385) e Muhammad Šīīn Mag̀ribī (m. 810/1408), per concludere con un maestro Naqšbandī contemporaneo di nome Abū l-Ḥasan Zayd Fārūqī (m. 1993). Questo excursus, sebbene breve e sommario, ripercorrendo più di mille anni consente di accertare la diffusione e la lunga fortuna del mezzo espressivo grafico nella storia del Tasawreuf, il quale rimane ancora oggi poco conosciuto e che solo raramente viene avvertito come una delle tecniche spirituali proprie del Sufismo.

Parole chiave: diagrammi, simbolismo visivo, sūra, șuwar, dāìra, dawāir, mitāl, amtila, šakl, aškāl, al-Ḥallāğğ, Ibn 'Arabī, Ḥaydar Āmulī, Š̉īinn Mag̉ribī, Abū l-Ḥasan Fārūqī.

$$
\therefore
$$

Abstract: This article provides introductory considerations on Visual Sufism, that is, on the vast and complex topic of the use of graphic representations in Sufi literature, focusing on one aspect in particular. That is about how these diagrams in many cases have been conceived by the Sufi masters who designed them and by their users as graphic tools to support spiritual realization. At the same time, through the analysis of the texts, it questions the reasons that led some Sufi thinkers to adopt this particular means of expression. In order to do so, authors of different periods have been taken into consideration, starting from al-Hallāğ (d. 309/922), passing through Ibn 'Arabī (d. 638/1240) -whose impulse appears decisive in the development of this phenomenon-then continuing with some eminent exponents of the Akbarian School such as Ḥaydar Āmulī (d. after 787/1385) and Muhammad Šìīn Mag̉ribī (d. 810/1408), concluding with a contemporary Naqšbandī master named Abū l-Ḥasan Zayd Fārūqī (d. 1993). This excursus, though brief and summary, by retracing more than a thousand years allows us to ascertain the diffusion and long fortune of the graphic means of expression in the history of Tasawreuf, which remains little known even today and is only rarely perceived as one of the spiritual techniques proper to Sufism.

Keywords: diagrams, visual symbolism, sūra, șuwar, dā’ira, dawāìr, mit̄āl, amtilla, šakl, aškāl, diagrammi, simbolismo visivo, al-Ḥallāğğ, Ibn 'Arabī, Ḥaydar Āmulī, Šīinn Mag̉ribī, Abū l-Ḥasan Zayd Fārūqī. 


\section{INTRODUZIONE}

Questo articolo è l'elaborazione di un intervento da me presentato al secondo simposio internazionale della Muhyiddin Ibn Arabi Society-Latina in Italia tenutosi in onore del Professor Alberto Ventura a Cosenza, presso l'Università della Calabria, alla fine di gennaio 2020. Il ricordo di quelle giornate di studio, di cui serbo viva memoria, mi è caro per varie ragioni. Prima di ogni altra cosa per la compagnia, perché il Prof. Ventura è stato colui che mi ha iniziato a questi studi, essendo stato il mio primo professore di islamistica all'Università di Napoli l'Orientale, perché il simposio è stato organizzato da stimati colleghi e amici (i quali sono anche i curatori di questo numero speciale di El Azufre Rojo) e perché è stata l'occasione per ritrovare studiosi e studiose che non vedevo da tempo e per fare la conoscenza personale di altri a me noti per fama e per averne letto le pagine, ma che fino ad allora non avevo avuto occasione di incontrare. Infine a rendermi il ricordo di quei giorni particolarmente piacevole è il fatto che quella sia stata l'ultima conferenza a cui ho partecipato prima che il Coronato istaurasse il proprio subdolo regno; un incontro, dunque, condotto in uno stato di cose che allora era ritenuto del tutto naturale, ma che, a rimembrarlo oggi, restituisce una sensazione analoga a quella che generano i ricordi d'infanzia, ovvero di essere stato un tempo incantato e irripetibile.

Il contenuto di queste pagine rappresenta una serie di considerazioni, necessariamente introduttive e circoscritte, su un tema vasto e complesso quanto poco studiato, ovvero non studiato in modo organico e unitario. Si tratta dell'utilizzo di rappresentazioni grafiche, nella maggior parte dei casi in forma diagrammatica, di carattere eminentemente esplicativo e simbolico, all'interno della letteratura del Sufismo'. Il 'Sufismo visivo' -è questa l'espressione che ho scelto di utilizzare per indicare questo fenomeno- è un tema ampio e sfaccettato, che si presta ad essere affrontato da vari punti di vista e che suggerisce un approccio multidisciplinare ${ }^{2}$. La forma materiale posseduta dai diagrammi e dalle figure oggetto di

$1 \mathrm{Su}$ tale argomento esistono vari studi singoli che prendono in considerazione in modo più o meno diretto tale o tal altra raffigurazione, o gruppo di raffigurazioni, contenute in un dato testo di Sufismo, o impiegate da un singolo autore, ma manca uno studio organico che abbia come oggetto principale tali elementi grafici. A mia conoscenza l'unico studio generale sulle raffigurazioni grafiche nel Sufismo, di carattere introduttivo e utile punto di partenza, è un articolo di Ahmet T. Karamustafa intitolato "Cosmographical Diagrams", in The History of Cartography, Volume 2, Book 1: Cartography in the Traditional Islamic and South Asian Societies, edito da J. B. Harley e David Woodward, Chicago-Londra, The University of Chicago Press, 1992, pp. 71-89. Una bibliografia esaustiva esula dai limiti imposti da un articolo. Rimandiamo alle successive note per alcuni studi sull'argomento.

$2 \mathrm{Nel}$ coniare questo neologismo mi sono ispirato al titolo del saggio dell'ebraista Giulio Busi Qabbalah visiva (Torino, Einaudi, 2005) in cui lo studioso ha preso in esame materiali grafici di carattere analogo nell'ambito della tradizione mistica ebraica. 'Sufismo visivo' è, come qualsivoglia definizione, termine imperfetto e limitato, avendo però al contempo il gran pregio di essere semplice e sintetico, 
analisi, soggette a innumerevoli varianti testuali all'interno della tradizione manoscritta (e a stampa) dei testi e tracciate all'interno di opere in gran parte ancora inedite, è materia di codicologia, filologia, di storia dell'arte e del libro. Il significato e l'utilizzo di quelle stesse figure rientra invece a vario titolo nella storia delle idee e del pensiero e nella storia delle religioni e della filosofia così come, da certi punti di vista, in discipline in apparenza assai diverse come le scienze cognitive.

Tra le molteplici prospettive da cui il Sufismo visivo può essere analizzato una sembra essere particolarmente attinente all'argomento di questo volume, dedicato ai metodi e alle tecniche di realizzazione spirituale nel Sufismo dell'epoca delle confraternite. Come venivano concepiti tali materiali grafici dai maestri spirituali che prima li idearono e poi li tracciarono materialmente e dagli originali destinatari delle loro opere? Si tratta di inerti immagini di corredo, oppure furono pensati, e dunque utilizzati, quali strumenti operativi a supporto della realizzazione spirituale? Per tentare di rispondere a questa domanda il metodo storico si affida necessariamente all'esame delle fonti scritte. Dallo studio della letteratura in oggetto sembra effettivamente emergere come l'implementazione di elementi grafici all'interno di una tradizione letteraria in cui aveva sempre prevalso l'aspetto testuale fosse dovuta alla volontà dei maestri di elaborare dei nuovi strumenti atti a facilitare la comprensione di concetti 'astratti' da parte dei propri lettori-discepoli. Se gli autori sono espliciti nel fare riferimento all'utilizzo tecnico dei diagrammi in qualità di strumenti didattici al fine di facilitare la comprensione teorica di concetti metafisici (la cui acquisizione era ritenuta parte integrante della realizzazione spirituale), contemporaneamente le medesime fonti sembrano suggerire la possibilità che tali elementi visivi fossero suscettibili di essere utilizzati dal lettoreiniziato anche come veri e propri supporti simbolici per una qualche forma di meditazione, in maniera forse non dissimile da quanto si riscontra in altre tradizioni spirituali (si pensi all'utilizzo dei mandala e degli yantra in ambito Indù e Buddista, o alle opere mnemotecniche di Giordano Bruno e alla corrente della cosiddetta Qabbalah Cristiana in Europa).

dunque comodo e utile al fine della comunicazione. Le mie ricerche sul Sufismo visivo in generale, e sulle opere del maestro sufi persiano Muhammad Šìīn Mag̉ribī (m. 810/1408, sul quale si veda infra) in particolare, sono state rese possibili grazie al supporto di due istituti di ricerca tedeschi. La mia riconoscenza va innanzitutto alla prof.ssa Judith Pfeiffer che è stata la prima a credere in questa linea di ricerca, dandomi la possibilità di lavorare a un progetto intitolato "Visual Sufism. A Case Study from 14th Century Tabriz: Shīrīn Maghribīss Short Metaphysical Treatises" all'interno dello Alexander von Humboldt Kolleg for Islamicate Intellectual History da lei diretto presso l'Università di Bonn. In una fase successiva questa linea di ricerca è stata portata avanti grazie a un progetto finanziato dalla Gerda Henkel Foundation intitolato "Shīrīn Maghribī: A Key Agent in the Transmission of Mystical Knowledge in 14th to 17 th Century Sufi Networks". 


\section{AL-ḤALLĀ $\check{G}$}

Il primo trattato di Sufismo di mia conoscenza in cui siano presenti elementi grafici è il Kìtāb al-Ṭ̂awasinn di al-Husayn al-Hallāğ (m. 309/922), un autore e un testo cari ad Alberto Ventura, il quale ne ha curato la prima traduzione italiana all'interno del volume intitolato Il Cristo dell'Islam ${ }^{3}$. Il problema principale di questo testo, come ricordato dallo stesso Ventura nell'introduzione, è dovuto alla «precaria trasmissione e [al]l'età relativamente tarda dei manoscritti che ne possediamo», e ai «disegni che al-Hallāj ha posto a illustrazione di alcuni temi cardinali del suo pensiero». «Queste raffigurazioni simboliche» infatti, «concepite come strumento visivo per meditare su verità inesprimibili a parole, sono state più volte deformate dai copisti e in alcuni casi risulta praticamente impossibile immaginarne l'aspetto originario $^{4}$.» Nonostante la trasmissione sia del testo che delle immagini sia compromessa, numerosi indizi suggeriscono che la meditazione sulle raffigurazioni in essa contenute fosse una delle chiavi fondamentali volute da al-Hallāğ per quest'opera. Ciò viene suggerito dal titolo stesso, il quale è un riferimento esplicito a due delle 14 'lettere separate' (al-hurüf almuqatta'a) poste in principio ad alcune sure del Corano e perciò dette anche 'lettere aprenti' (hurūf al-fawātih/fawātih al-suwar $)^{5}$. Di tali lettere infatti, a causa del loro significato enigmatico che non restituisce nessuna parola di senso compiuto, e della posizione 'isolata' che esse occupano nel testo Coranico, la forma e il suono risaltano prima del significato (cf. Figura 1), sul quale gli esegeti discettano da secoli e del quale i maestri del Sufismo hanno fornito numerose interpretazioni simboliche ${ }^{6}$.

3 Al-Husayn Ibn Manșūr al-Hallāj, Il cristo dell'Islam. Scritti mistici, a cura di Alberto Ventura, Milano, Arnoldo Mondadori Editore, 2007.

4 Ibid., pp. 103-104.

5 Le due lettere Ṭăa e Sīn che danno il titolo al testo di al-Hallāğ si trovano all'inizio della Sura della Formica (Cor. 27:1). Per una sintesi della letteratura scientifica e delle opinioni degli studiosi sulla questione delle 'lettere isolate' si veda Roberto Tottoli, Leggere e studiare il Corano, una guida, 2.2. Le lettere misteriose, 2021, Istituto per l'Oriente C.A. Nallino, Roma. Per alcuni riferimenti all'esegesi delle lettere isolate in ambito Sufi si veda Alexander D. Knysh, "Șūfism and the Qur’ān" in Encyclopaedia of the Qur'ān, Jane Dammen McAuliffe (ed.), Leida-Boston, Brill, 2006, vol. 5, pp. 137-159. In virtù delle loro caratteristiche le lettere isolate svolgo un ruolo rilevante nella Scienza delle lettere ( $\mathrm{Ilm}$ alhurüf), ovvero in quella 'gematria islamica' che tanta parte ha all'interno del Sufismo così come della letteratura ermetica, alchemica e magica in ambito islamico. Sul tema si veda e.g. Jean Canteins, $L a$ voie des lettres, tradition cachée en Israël et en Islam, Parigi, Albin Michel, 1981.

6 Un altro aspetto importante che si ricollega al tema del Sufismo visivo è il carattere 'intermedio' delle lettere isolate: lettere sì, ma non ancora parole di senso compiuto; già all'interno del testo Coranico, ma contemporaneamente 'isolate'. Tale carattere 'intermedio' infatti è proprio quello che si rivela essere anche una delle caratteristiche principali dei diagrammi simbolici inseriti dai maestri sufi nei loro testi, ovvero immagini-forme afferenti al 'mundus immaginalis', simboli che alludono alle idee eterne e sovraformali all'interno del mondo sensibile (si veda infra). 


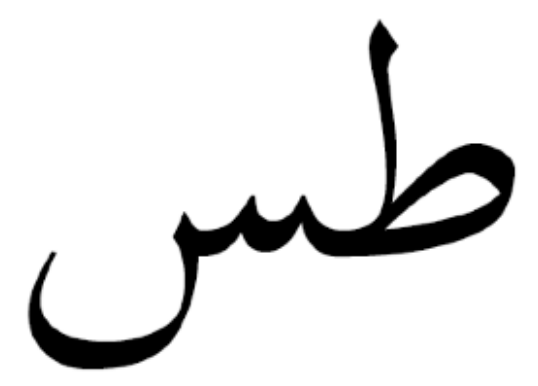

Figura 1: Raffigurazione delle due lettere Ṭā̄ e Sīn che danno il titolo all'opera di al-Hallāğ in caratteri arabi così come si presentano all'inizio della Sura della Formica (Cor. 27:1)

La centralità del simbolismo visivo all’interno del testo di al-Hallāğ è ribadita dai titoli di alcune delle sezioni in cui è suddiviso, tra cui troviamo ad esempio "Il Ṭāsīn della circonferenza" (T⿱ $\bar{a} s \bar{n}$ al-dā îra) o, ancora, "Il Ṭāsīn del punto" (Ṭāsin al-nuqta) ${ }^{7}$. L'associazione di figure simboliche a precisi concetti geometrici da parte di al-Hallāğ offre l'occasione per ricordare che una larga parte delle figure e dei digrammi che costituiscono il corpus del Sufismo visivo presentano forme geometriche esplicite e che in questo campo esiste dunque una strettissima relazione (spesso una vera e propria sovrapposizione) tra simbolismo visivo e simbolismo geometrico ${ }^{8}$. Un altro indizio della relazione tra il concetto di lettere isolate e quello di forme simboliche secondo al-Hallāğ è costituito dal fatto che egli intende le lettere T⿳ăà e Sīn del titolo quali nomi propri delle rappresentazioni simboliche di cui è disseminato il testo, come si evince ad esempio dal titolo dell'undicesima sezione: "Questo è l'undicesimo dei Ṭawāsīn. Eccone la raffigurazione (șurra, lett. "forma")"9.

7 L’edizione critica di riferimento è Paul Nwyia, "Hallāğ. Kitāb al-Ṭawāsīn. Édition nouvelle", Mélanges de l'Université Saint foseph 47 (1972), pp. 183-238, pp. 197 e 199. Cf. al-Hallāj, Il cristo dell'Islam, pp. 116 e 119.

$8 \mathrm{Ci}$ troviamo cioè difronte a un tipo di simbolismo visivo a tendenza geometrica e astratta piuttosto che figurativa, che ben si confà al contesto islamico. Così almeno in linea di principio, sebbene esistano anche in questo campo numerose eccezioni, tra le quali raffigurazioni antropomorfiche. Ciò si riscontra in vari contesti storici e geografici, si vedano per alcuni esempi Frederick De Jong, "The iconography of Bektashiism. A survey of themes and symbolism in clerical costume, liturgical objects and pictorial art", Manuscripts of the Midle East 4 (1989), pp. 7-29 e Fabrizio Speziale, "Il simbolismo mistico del volto umano nel trattato (in urdu) Sürat-i ma qūma-yi suwari Slm di Karīm Allāh 'Āshiq”, Fournal Asiatique 295.2 (2007), pp. 439-59. Un caso di 'evoluzione' da raffigurazione astratta a raffigurazione antropomorfica di un diagramma nel corso dei secoli in ambito Sufi è discusso in Giovanni Maria Martini "Shīrīn Maghribīs (d. 810/1408) Visual Sufism: Diagrams, Intellectual Networks and the Transmission of Spiritual Knowledge in 14th Century Tabriz and beyond", di prossima pubblicazione.

9 Nwyia, "Hallāğ", p. 215; Al-Hallāj, Il cristo dell'Islam, p. 145. 


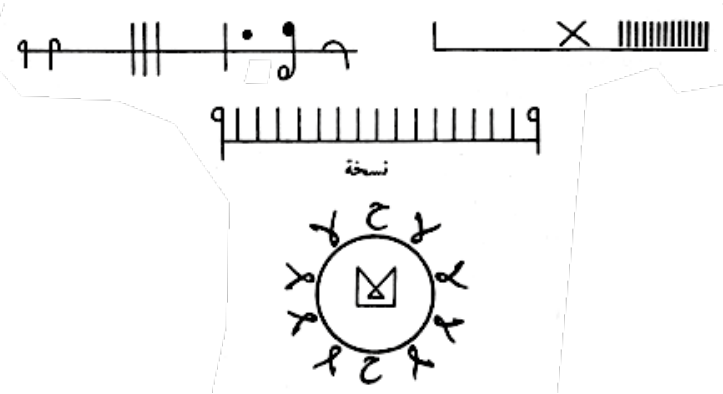

Figura 2: al-Ḥallāğ, Kitāb al-Ṭawāsinn, raffigurazione dell'undicesimo Ṭāsīn ${ }^{10}$

In ogni caso l'indicazione principale del fatto che il fulcro dell'opera di al-Hallāğ siano le rappresentazioni simboliche in esso contenute è che la parte scritta del testo nella maggior parte dei casi non sia in realtà che una descrizione allusiva dei significati di tali figure e un esortazione alla loro meditazione, come in questo passo:

«Ecco la raffigurazione della realtà, di quelli che la cercano, delle sue porte e dei mezzi per ottenerla:

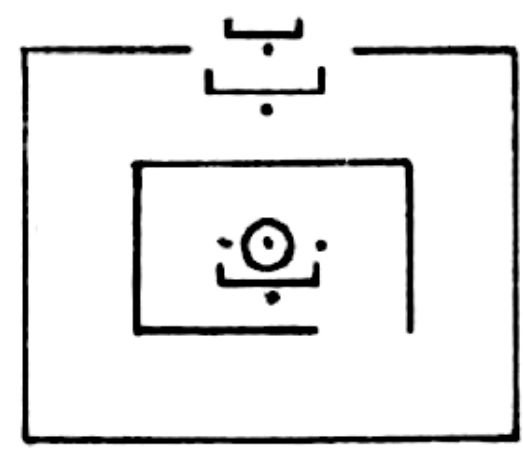

Figura 3: al-Ḥallāğ, Kitāb al-Ṭawāsinn ${ }^{11}$

La B esterna rappresenta chi è pervenuto alla soglia della realtà, la seconda B simboleggia chi ha varcato quella soglia ma poi ha smarrito la strada, la terza raffigura colui che vaga perduto nei deserti della realtà della realtà.

Indietro! Chi potrebbe mai penetrare nel cerchio, se la porta è sbarrata e il postulante viene respinto? Il punto della B superiore rappresenta l'aspirazione di colui che cerca, quella della B inferiore il suo ritorno all'origine e infine quello della B intermedia la sua stupita incertezza. ${ }^{12}{ } \gg$

10 Nwyia, "Hallāğ", p. 215, Al-Hallāj, Il cristo dell'Islam, p. 145.

11 Nwyia, "Hallāğ", p. 197; Al-Hallāj, Il cristo dell'Islam, p. 116.

12 Traduzione di Alberto Ventura in Al-Ḥallāj, Il cristo dell'Islam, p. 116. 


\section{IBN 'ARABī}

Nei secoli immediatamente successivi al caso eccezionale di al-Hallāğ le rappresentazioni grafiche all'interno di opere di Ṭaṣawwuf rimangono assai rare. Due eccezioni paiono essere al-Gazālī (m. 505/1111) nell'undicesimo secolo, il quale include un paio di immagini nello Ihy ă’ 'ulūm al-Dīn, e Šams al-Dīn al-Daylāmī nel dodicesimo, il quale include raffigurazioni in alcune delle sue opere inedite ${ }^{13}$. È però nel tredicesimo secolo che si assiste a una maggiore diffusione e affermazione dell'uso di elementi visivi nella letteratura e nelle pratiche del Sufismo. Tre importanti maestri che furono tra loro contemporanei (e forse in contatto diretto l'uno con l'altro) possono essere considerati gli iniziatori di questa nuova tendenza, ma tra di essi è uno in particolare ad aver giocato un ruolo determinante a causa della sua importanza e dell'influenza eccezionale che i suoi testi e le sue dottrine esercitarono sulle generazioni successive. Il riferimento è a Muhȳì al-Dīn Ibn al-'Arabī (m. 638/1240), il quale ha fatto ricorso a rappresentazioni grafiche in diverse opere, tra cui Il libro della produzione dei cerchi (Kitāab inšà' al-dawā'ir), Il nodo del sagace (Uqlat al-mustawfiz), e le monumentali Rivelazioni meccane (al-Futūhāt al-makkiyya). Contemporanei di Ibn 'Arabī sono l'enigmatico maestro Kubrawī persiano Sa'd al-Dīn Hamūya (m. 649/1252), di cui si ricordano i criptici diagrammi contenuti nel tutt'ora inedito Libro dell'Amato (Kitāb al-Mahbūb), e il famoso Sufi magrebino Aḥmad al-Būn̄̄ (m. 622/1225 o 630/1232-3) ${ }^{14}$. Quest'ultimo, noto soprattutto (e non in modo del tutto proprio) quale autore dell'opera di magia più popolare nel mondo musulmano, Il Sole delle conoscenze (Šams al-ma (âriff), compose in realtà numerosi testi sufi di argomento dottrinale, questi ultimi ancora inediti e poco studiati, nei quali Būnī utilizza a più riprese diagrammi per illustrare le proprie elaborazioni cosmologiche e metafisiche.

13 Abū Ḥāmid al-Ġazālī, Ihyā’ 'ulūm al-dīn, Cairo, Dār al-Šacb, 1388-90/1969-71, pp. 351, 1112 e 1113 . Sul corpus Daylamiano si vedano A. J. Arberry, "The Works of Shams al-Dīn al-Dailamì", Bulletin of the School of Oriental and African Studies, University of London, 29 No. 1 (1966), pp. 49-56 e Gerhard Böwering, "The Writings of Shams al-Dīn al-Daylamī”, Islamic Studies, 26, No. 3 (1987), pp. 231-236. Sulla questione specifica dell'utilizzo dei diagrammi da parte di Daylamī si veda Elizabeth R. Alexandrin, "Witnessing the Lights of the Heavenly Dominion Dreams, Visions and the Mystical Exegeses of Shams al-Dīn al-Daylamı̄”, in Dreams and Visions in Islamic Societies, Özgen Felek e Alexander D. Knysh (ed.), Albany, State University of New York Press, 2012, pp. 215-31.

14 Un'edizione critica del Kitāb al-Mạ̣būb di Sa'd al-Dīn Hamūya è in preparazione da parte di Elizabeth R. Alexandrin e Paul Ballanfat. Alexandrin ha analizzato vari aspetti dei diagrammi contenuti nel Kitāb al-Mahbūb e in altre opere di Hamūya in un intervento intitolato "Secret Alphabets and Sealed Texts in Three Unedited Works of Sa'd al-Dīn Hamūyeh" durante un workshop intitolato "Visualizing Sufism" da me organizzato presso lo Alexander von Humboldt Kolleg for Islamicate Intellecual History, Università di Bonn, il 14 maggio 2018. La pubblicazione dei risultati di tale studio in forma di articolo è prevista negli atti del workshop. I diagrammi presenti in una delle più importanti opere inedite di Aḥmad al-Būnì è stata oggetto di una presentazione di Noah Gardiner dal titolo

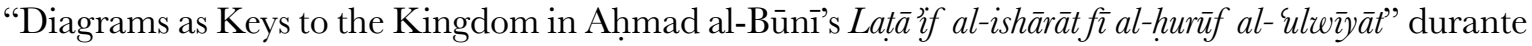
il medesimo workshop. Anche in questo caso è prevista la pubblicazione dei risultati di tale studio sotto forma di articolo negli atti del workshop. 
Tenuto conto della grandiosa elaborazione dottrinale di Ibn 'Arabī non c'è da stupirsi che sia stato il grande maestro andaluso a fornire una delle prime introduzioni teoriche all'utilizzo di raffigurazioni simboliche in ambito Sufi. Ciò avviene già in una delle sue opere giovanili, redatta quando egli si trovava ancora nel 'Maghreb' e prima del suo lungo viaggio verso oriente, opera nella quale il ruolo centrale delle 'forme' è messo in evidenza fin dal titolo, ovvero il già citato Libro della produzione dei cerchi, il cui titolo completo, piuttosto esplicativo al riguardo, recita: "La produzione dei cerchi comprendenti l'analogia dell'Uomo con il Creatore e con le creature sotto forme sensibili intellegibili ( fì l-șwar al-mahsüsa al-ma'qüla) e nelle creature, e sulla discesa su di lui delle realtà essenziali all'interno dei canali dei legami universali sottili’" ${ }^{5}$. La centralità del tema della raffigurazione è suggerito da Ibn 'Arabī nella prima frase della hutba, subito dopo la Basmala, in cui egli suggerisce una relazione tra Dio e l'Uomo attraverso le idee di 'forma' e di 'somiglianza' e facendo di queste relazioni, $a b$ inverso, degli strumenti che possono consentire all'Uomo di pervenire alla conoscenza di Dio: «La lode spetta a Dio il quale ha creato l'Uomo a Sua immagine (süra, anche "forma"), gli ha donato il privilegio di conoscere il Suo segreto e ha fatto della somiglianza (al-mudāhāh) e dell'emulazione della bontà e della bellezza $(a l-m u b \bar{a} h \bar{a} h)^{16}$ due premesse (muqaddimatayn) per validare il risultato costituito dalla conoscenza di Lui. ${ }^{17}$ » Riguardo quindi all'uso di raffigurazioni, nell'introduzione vera e propria leggiamo:

«Quando Dio — che Egli sia glorificato — mi fece conoscere le realtà delle cose

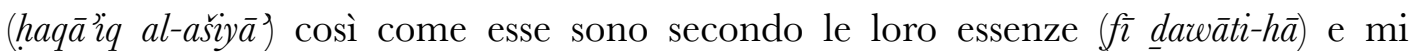
istruì mediante svelamento intuitivo sulle realtà delle loro relazioni e correlazioni

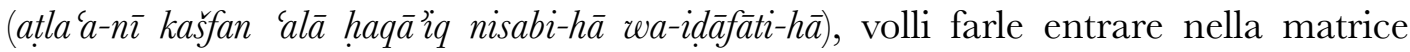
della rappresentazione sensibile (aradtu an adhala-hā fì qālib al-tašk $\bar{\imath}$ al-hissī ) al fine di avvicinare al mio compagno 'Abd Allāh Badr al-Ḥabašì il luogo ove queste ultime

15 H. S. Nyberg, Kleinere Schriften des Ibn 'Arabī, nach Handschriften in Upsala und Berlin zum ersten Mal herausgegeben und mit Einteitung und Kommentar versehen, Leida, E.J. Brill, 1919, p. 5. Cf. Trad. Francese in Ibn 'Arabî, La production des cercles, Paul Fenton e Maurice Gloton (ed. e trad.), Parigi, Édition de l'Éclat, 1996, p. 4; Cf. Trad. Italiana in Maurizio Marconi, "Il libro della produzione dei cerchi di Ibn 'Arabī", El Azufre Rojo, 5 (2018), pp. 33-102, p. 37. La traduzione di Marconi è basta sul manoscritto più antico conosciuto del testo, copiato nell'anno 655 dell'Egira, solo quindici anni dopo la morte di Ibn 'Arabī, sulla base dell'autografo che era in possesso di 'Abd Allāh Badr al-Habašīi, l'inseparabile compagno di Ibn al-'Arabī a cui il trattato fu espressamente dedicato dal grande Sufi andaluso (si veda infra).

16 Questo termine è di difficile interpretazione. Esso significa letteralmente competere, rivaleggiare l'un l'altro per bellezza o bontà, o emulare qualcuno nelle qualità positive. I traduttori differiscono nelle loro scelte. La mia interpretazione del passo, da cui deriva la mia scelta di traduzione, è la seguente: l'Uomo avendo il privilegio di potersi porre in analogia con Dio e sforzandosi di assomigliarGli (provando ad acquisirne i caratteri di perfezione) può pervenire alla conoscenza di Lui.

17 Nyberg, Kleinere Schriften, p. 3; cf. Ibn 'Arabî, La production des cercles, p. 1 e Marconi, "Il libro della produzione dei cerchi", p. 37. 


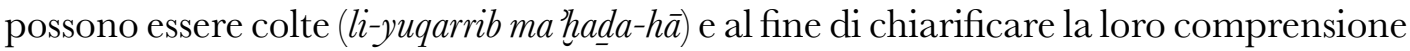
a colui la cui vista fa fatica ad afferrale $[\ldots] .{ }^{18} \gg$

In queste righe Ibn 'Arabī dice molto di più di quanto possa sembrare a prima vista. Ci parla dell'esistenza di realtà essenziali trascendenti (haqü $q$ ), del fatto di averle conosciute tramite svelamento intuitivo (kašf), quindi della sua volontà di far entrare (adhala) queste realtà in una matrice formale e sensibile (qâlab al-taškñl al-hiss $\vec{\imath}$ ) e che lo scopo di questa operazione è avvicinare il punto di accesso a queste realtà (li-yuqarrib ma hhad $a-h \bar{a})$, ovvero creare dei 'luoghi' formali dove queste realtà trascendenti possano essere più facilmente afferrate; il tutto motivato dal desiderio di facilitare coloro che non riescono a cogliere tali realtà trascendenti direttamente nella loro essenza sovraformale. In poche parole Ibn 'Arabī sta esplicitando la propria volontà di costruire delle raffigurazioni simboliche visive ad uso di coloro che stanno intraprendendo la via spirituale. Tali raffigurazioni simboliche danno corpo a un paradosso, e hanno natura duplice, poiché partecipano contemporaneamente delle realtà essenziali trascendenti così come delle limitazioni proprie alla manifestazione formale sensibile. È questa la natura intima del Sufismo visivo che esso condivide con tutte le raffigurazioni simboliche. Le realtà essenziali sono principi troppo universali per possedere una forma nel vero senso della parola, ma colui che ha realizzato quelle realtà per mezzo di svelamento intuitivo può 'fabbricare' un'immagine simbolica delle stesse. Questo è un punto fondamentale, sul quale Ibn 'Arabī ritorna indirettamente in un altro passo della stessa opera, quando introducendo il "Diagramma sella Sostanza universale" (al-ğadwal al-hayūlān $\vec{\imath}$ afferma che:

«Questa sarebbe la rappresentazione della sua forma, se essa avesse una forma (wa-hā $\underline{d} \bar{a}$ mitāl șurati-hā law kānat la-hā șüra) e ciò tuttavia (walakin, ovvero nonostante la Sostanza universale non possegga una forma) poiché essa è per noi intellegibile e scibile (lammā

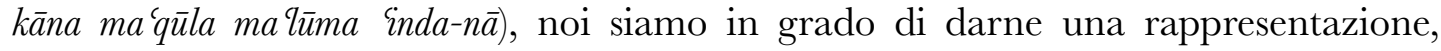
seppure sintetica (qadarnā 'alà ibāzi-hā, walakin muğmalatan). ${ }^{19}{ }{ }$

18 Nyberg, Kleinere Schriften, p. 3-4; cf. Ibn 'Arabî, La production des cercles, p. 2 e Marconi, "Il libro della produzione dei cerchi", p. 39.

19 Nyberg, Kleinere Schriften, pp. 24-25; cf. Ibn 'Arabî, La production des cercles, p. 28 e Marconi, "Il libro della produzione dei cerchi", p. 72. 


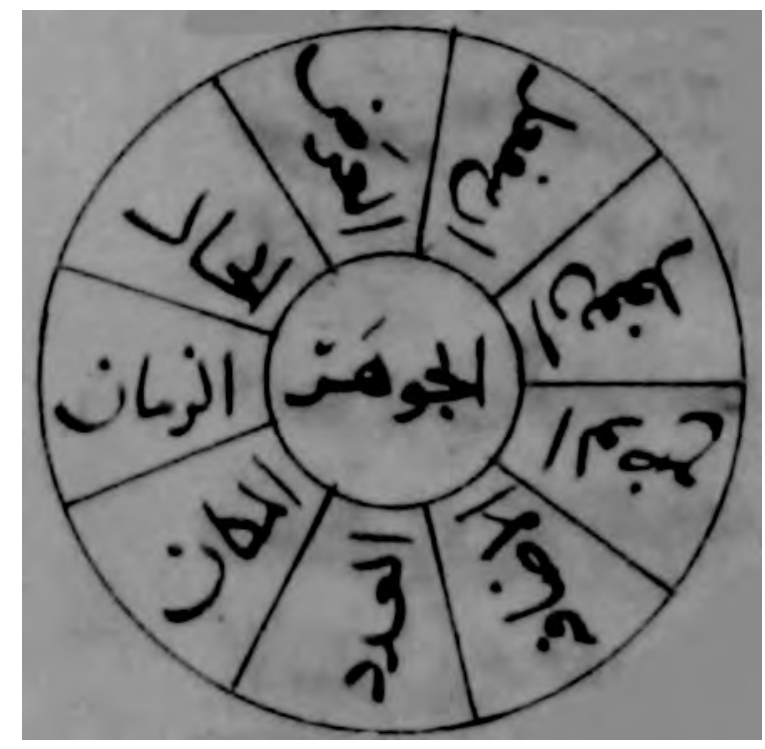

Figura 4: Ibn 'Arabī, Kitāb Inšă'al-dawāìr, "Diagramma della Sostanza Universale" (alĞadwal al-hayūlān $\vec{\imath}$, MS Manisa, İl Halk Kütüphanesi 1183, f. 131r²0.

Ł̀ possibile affermare che la maggior parte delle figure che si incontrano nella letteratura Sufi ricadono concettualmente in questa categoria di immagini ben descritta da Ibn 'Arabî: sono cioè raffigurazioni simboliche sensibili di realtà sovraformali ${ }^{21}$. In questo senso ciascuno degli innumerevoli disegni disseminati nella letteratura del Sufismo può essere considerato una soglia, un luogo di passaggio capace di condurre l'iniziato che lo medita verso realtà eterne che trascendono i limiti dello spazio e del tempo ${ }^{22}$.

$20 \mathrm{Al}$ centro del diagramma è riportato il termine al-ğawhar ("la sostanza"); in senso antiorario, partendo da ore dodici, leggiamo: al-'arad ("l'accidente"); al-ḥal ("lo stato"); al-zamān ("il tempo"); al-makān ("il luogo"); al-'adad ("il numero/la quantità"); al-idāfa ("la relazione"); al-wad'("la posizione"); an yaf'al ("azione"); an yanfa \&l ("passione"). Per qualche osservazione su corrispondenze e divergenze tra il contenuto di questo diagramma di Ibn 'Arabī e le dieci categorie aristoteliche si veda Ibn 'Arabî, $L a$ production des cercles, p. 28.

21 In questo caso specifico legate al senso della vista. Ciò non toglie che lo stesso principio si applichi agli oggetti di conoscenza sottoposti agli altri sensi. Si pensi al ruolo centrale del suono e dunque del simbolismo auditivo nelle tecniche iniziatiche del Tașawwuf (e.g. recitazione/audizione di formule incantatorie).

22 Il lettore-osservatore dunque non deve in nessun caso identificare queste immagini-simbolo con le realtà essenziali tout court, né ritenere che esse ne siano la forma, se non intendendo questo termine in senso strettamente simbolico. Tali raffigurazioni non sono l'oggetto ultimo di conoscenza, bensì un senhal che allude a quest'ultimo. Sul fatto che secondo i modelli cosmologici generalmente adottati dai maestri del Sufismo gran parte dei concetti oggetto di raffigurazioni simboliche nei loro testi precedano le determinazioni spazio-temporali (e dunque non possano essere per definizione sottoposti a 


\section{HAYDAR ĀMULì}

L'ampio utilizzo di immagini da parte di Ibn 'Arabī troverà degnissimi eredi nelle generazioni successive. Trattando questo aspetto è d'obbligo citare il nome di Haydar Āmulī (m. dopo il $787 / 1385)$. Il grande maestro persiano del $14^{\circ}$ secolo, famoso per la sua sintesi tra Sufismo di matrice Akbariana e gnosi sciita, è infatti, contemporaneamente, uno dei maestri che più hanno voluto e saputo utilizzare il potente strumento costituito dai diagrammi ${ }^{23}$. Negli scritti di Āmulī pervenuti fino a noi se ne contano più di trenta, distribuiti all'interno di due delle sue opere più importanti, il commentario ai Fușus al-hikam (28 diagrammi) e il suo commentario coranico (9 diagrammi, più 2 ricostruiti). È dai Prolegomeni al Commentario ai Fușus al-hikam che traggo il seguente passo, in cui il maestro di Amol illustra la dottrina che sottende all'utilizzazione di questi simboli visivi:

«Lo scopo di tutti i diagrammi circolari (al-ġarad min al-dawāir kulli-hāa, ovvero le 28 immagini incluse nel testo) è di rappresentare (taškīl) le conoscenze divine (al-ma ârif alilāhiyya) e le realtà dominicali (al-haqā iq al-rabbāniyya) che ci sono pervenute tramite la via dello svelamento intuitivo e del gusto spirituale (bi-tarīq al-kašf wa-l-dawq) [prima] all'interno della forma di rappresentazioni simboliche intellegibili (fì sürat al-amtila al-'aqliyya), e successivamente all'interno della forma di rappresentazioni sensibili (tumma fì șurrat al-awd $\bar{a}^{\prime}$ al-hissiyya), per facilitare la comprensione dell'obiettivo finale e l'ottenimento di ciò che è agognato (tashīlan li-idrāk al-maqșūd wa-tahsīl al-matlūb).

[...] E in realtà le parole dell'altissimo Dio è la Luce dei cieli e della terra, e si rassomiglia la Sua Luce a una Nicchia, in cui è una Lampada, e la Lampada è in un Cristallo, e il Cristallo è come una Stella lucente (Gor. 24:35) sono un'allusione a questo concetto, poiché la

tali condizioni), si vedano alcuni riferimenti espliciti di Ibn al-'Arabī e Šìrīn Mag̉ribī citati in Giovanni Maria Martini, "al-Nuzha al-Sāsāniyya by Shīrīn Maghribī (d. 810/1408): A Recently-Discovered Cosmological Treatise in Persian of the School of Ibn al-'Arabï”, Oriens, 49 (2021), pp. 35-94, p. 80 e relative note.

23 Sui diagrammi in Āmulī si vedano Henry Corbin, "Le paradoxe du monothéisme", in Eranos fahrbuch 45 (1980): 69-133. Si vedano anche le analisi e i passi raccolti da al-Sayyid Muhsin al-Mūsawī al-Tabrīzī nell'introduzione dell'edizione del commentario coranico di Āmulī da lui curata: Haydar

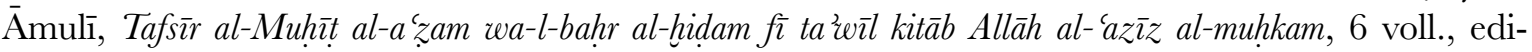
to da al-Sayyid Muḥsin al-Mūsawī al-Tabrīzī, Qom, Mu’assasa-yi farhangī va našr-i nūr 'alā nūr, 1428h.š./1385/2007, vol. 1, pp. 96-118. Più recentemente Eliza Tasbihi ha presentato uno studio sui diagrammi nel Naș al-nusūs intitolato "Esoteric Deliberations on Visionary Unveiling: Mystical Knowledge From Haydar Āmulī’s (d. 1385) Naș al-nusūs fî̀ sharh al-Fusūs al-Hikam" durante il già citato workshop "Visualizing Sufism". Sullo stesso tema Tasbihi a successivamente pubblicato l'articolo "Visionary Perceptions through Cosmographical Diagrams: Mystical Knowledge from Haydar Āmulī’s Nașs al-nusūs fì sharh Fușūs al-hikam”, JMIAS, 69 (2021), pp. 31-81. 
nicchia (al-miskkāh) è un'allusione al mondo sensibile ('`alam al-hiss), il cristallo (alzuğăğa) [un'allusione] al mondo intellettuale ('âlam al-'aql), e la lampada (al-miṣbāh) [un'allusione] al mondo dello svelamento intuitivo ('âlam al-kašhf). ${ }^{24}{ }^{2}{ }^{\prime}$

Āmulī illustra in un modo suo proprio la stessa idea già espressa da Ibn 'Arabī nel Libro della produzione dei cerchi. Per aiutare la comprensione di questo concetto il maestro persiano ricorre a un'interpretazione allegorica del ben noto Versetto della Luce, illustrando un processo di condensazione delle realtà divine suddiviso in tre fasi, tre passaggi attraverso altrettanti gradi di determinazione successivi.

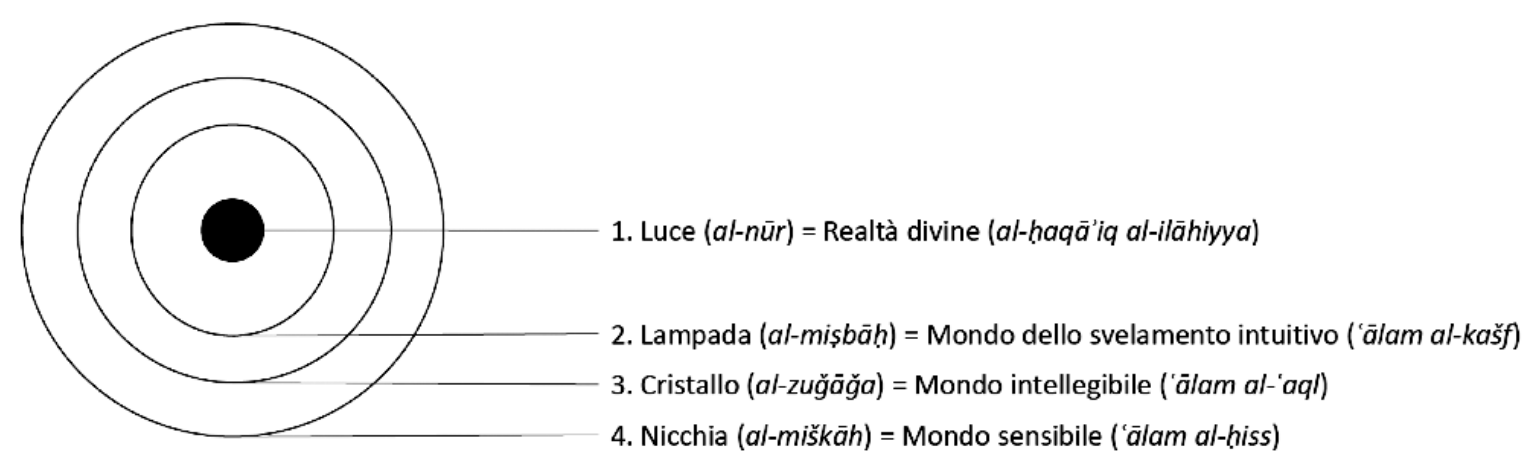

Figura 5: Rappresentazione del modello esposto da Haydar Āmulī nei Prolegomeni al Naș al-nușuss.

Le realtà divine, paragonabili alla luce del famoso versetto, in un primo momento vengono intuite dall'iniziato sotto forma di svelamento intuitivo, sovraformale e non discorsivo. Solo successivamente a questo svelamento una forma intellegibile di queste realtà si forma nell'intelletto dell'iniziato. La rappresentazione grafica e sensibile di queste stesse realtà, ovvero le immagini punto di partenza di questo studio, non sono che il risultato finale e più solidificato di tale processo di condensazione ${ }^{25}$.

24 Haydar Āmulī, al-Muqaddimāt min Kitāb Nașs al-nusūs fì šarh Fusūus al-hikam li-Muhȳ al-Dīn Ibn al-'Ar$a b \bar{\imath} /$ Le texte des textes (NASS AL-NOSUS), commentaire des "Fosûs al-hikam» d'Ibn 'Arabî, Les prolégomènes, Henry Corbin e Osman Yahya (ed.), Teheran-Parigi, Département d'iranologie de l'Institut Franco-Iranien de recherche-Librairie d'Amérique et d'Orient Adrien-Maisonneuve, 1975, p. 31.

25 La breve analisi di Āmulī si presterebbe a considerazioni ulteriori. Tra queste il fatto che le realtà divine, paragonate qui alla luce del noto versetto, secondo l'autore sono assolutamente trascendenti. Prova ne è che anche la modalità suprema di conoscenza menzionata da Āmulī, lo svelamento intuitivo, non si identifica con esse, lasciando quindi permanere un'alterità. A questo proposito è lecito pensare che esista una quarta modalità di conoscenza (dopo quella sensibile, intellettuale e intuitiva) che corrisponde all'identificazione di oggetto e soggetto di conoscenza. Nel caso specifico della metafora coranica utilizzata da Āmulī dopo aver visto la luce, averla intelletta e averla intuita, l'ultimo passo è divenire luce. Un'altra considerazione è che 
Āmulī ritorna più volte su questo concetto nella sua opera. In un passo del suo Tafsìr, anch'esso, come ricordato, costellato di diagrammi, leggiamo:

«Lo scopo di questo [discorso] è che tu sappia che nella maggior parte dei passi di questo libro si menzionano i significati intellegibili (al-ma ânñ al-ma'qūla) e le conoscenze risultanti dallo svelamento intuitivo (al-ma'ārif al-kašffyya) sotto forma di figure e di cerchi $(f \hat{\imath}$ șurat aškāl wa-dawäär); questo e nient'atro: ovvero far pervenire i significati

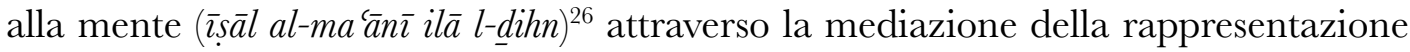
formale sensibile (bi-wāsițat al-taškil al-ḥissī al-șuwarì). ${ }^{27}{ }{ }$

Ma l'analisi di Āmulī non si ferma qui. Il maestro persiano fornisce ulteriori spiegazioni in merito alle ragioni per cui una rappresentazione sensibile dovrebbe facilitare la comprensione delle realtà intellettuali e metafisiche. Egli lo fa sulla base di un personalissimo studio dei processi cognitivi dell'essere umano, osservando una tendenza innata dell'individuo a rifuggire le questioni puramente intellettuali, mentre quelle medesime questioni intellettuali gli divengono immediatamente più congeniali allorquando vengono rivestite di una forma esteriore percepibile dai sensi:

«Nei nostri intelletti abbiamo osservato che se vediamo la forma di una questione intellettuale all'interno di rappresentazioni sensibili i nostri cuori propendono verso

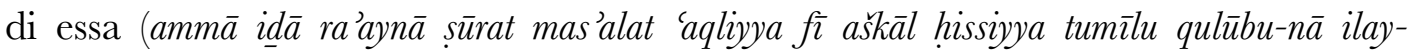
$h \bar{a})$ dopo che [invece] in precedenza, in assenza di detta forma [sensibile], essi ne rifuggivano (ba'd an kānat mutafarriqatan 'an-hā fì gaayr tilka al-șüra), poiché abbiamo notato che moltissime questioni ci rimangono difficili [da comprendere] nella loro forma intellettuale mentre ci divengono più facili sotto forma sensibile (katīi min al-

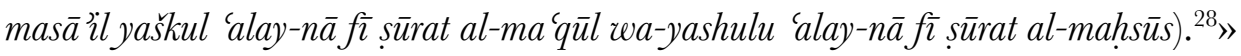

Āmulī non si accontenta di osservare e descrivere questo fenomeno; ne fornisce altresì una spiegazione e lo fa chiamando in causa un elemento centrale della fisiologia sottile, ovvero l'anima (al-nafs). Il maestro spiega infatti come sia l'anima dell'individuo ad essere

secondo questa prospettiva non v'è contrapposizione alcuna tra intelletto e svelamento intuitivo (dunque tra via intellettuale e via spirituale, ovvero tra 'filosofia' e Sufismo), i quali coesistono all'interno di una gerarchia. 26 La definizione di dihn, ovvero "cogitazione", "mentale", "mente", secondo al-Ǧurğānī nel noto $L i$ bro delle definizioni è la seguente: "la facoltà dell'essere umano che coordina i sensi esterni e interni per permettergli di acquisire le scienze. L'attitudine (isti $d \bar{a} d$ ) perfetta che permette di acquisire le science e le conoscenze per riflessione (fikr)", cf. 'Alī b. Muhammad al-Jurjānī, Kitāb al-Ta'rî̀āt, Maurice Gloton (trad. e ed.), Pierre Lory (pref.), Teheran, Presses Universitaieres d'Iran, 1994, p. 204.

27 Āmulī, Tafsìr al-Muhīt al-a żam, vol. 5, p. 198, cf. vol. 1, p. 107.

28 Āmulī, Tafsìr al-Muhịt al-a'zam, vol. 5, p. 198, cf. vol. 1, p.107. 
innatamente attratta dalle forme sensibili e che ciò avviene a causa della architettura profonda del microcosmo per cui l'anima dipende dai sensi per la conoscenza degli enti sensibili e par la memorizzazione degli enti intellegibili:

«In generale è presente un legame d'amore (ta'alluq al- $i \check{s} q)$ tra l'anima e i sensi, causato dal fatto che i sensi sono uno strumento (älah) per mezzo del quale l'anima percepisce i sensibili e memorizza gli intellegibili (bi-hā tudrik al-mahsūsāt wa-tahfuz al-máqūlāt), cosicché ogniqualvolta i significati sono contenuti nella forma dei sensi ciò è meglio e più congeniale, e l'intendimento di tali significati attraverso detta forma è più facile

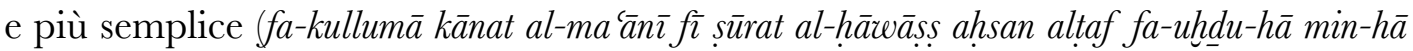
yakūn ashal wa-aysar). ${ }^{29} \gg$

Apprendiamo così che una delle ragioni principali dell'impiego di elementi visivi da parte dei maestri del Taṣawwuf è superare l'opposizione dell'anima, o meglio trasformare l'anima da 'nemico naturale' a potente alleato. Āmulī aggiunge un'altra osservazione di notevole interesse. Seguendo il ragionamento esposto nei passi precedenti, secondo il quale i diagrammi da lui approntati non sarebbero altro che rappresentazioni sensibili di realtà intellegibili astratte costruite ad hoc per agevolarne l'intendimento ai lettori-iniziati, egli ci ricorda che tali immagini sono fatte della stessa sostanza dei sogni. Esse cioè hanno una natura intermedia, partecipando in qualche maniera del Mundus imaginalis:

«La veridicità di questo [meccanismo secondo il quale sono state composte le raffigurazioni incluse in questo libro] è confermata dalla visione in sogno durante il sonno (al-rujyā fì l-nawm). Poiché la visione in sogno in realtà altro non è che l'apparizione del mondo intellegibile in forma sensibile (mušāhadat 'âlam al-ma'qūl fī sürat al-mahsüs) causata dalla forza operativa del senso interno in questo peculiare stato (li-quwwat tașarruf al-ḥiss al-bātin fì tilka al-ḥala), nello specifico la facoltà immaginativa particolarizzata (al-quwwa al-hayāliyya al-muqayyada), la quale corrisponde (all'interno del singolo individuo) alla Facoltà Immaginativa assoluta designata col nome di Mundus imaginalis ('ālam al-mițāl), il quale comprende il Trono, lo Sgabello, i cieli, le terre e tutti gli esseri esistenziati che in essi si trovano. ${ }^{30}$ »

29 Āmulī, Tafsīr al-Muhīt al-a'zam, vol. 5, p. 198, cf. vol. 1, p. 107. Āmulī ritorna sulla questione del rapporto tra l'anima e i sensi e sulle implicazioni di quest'ultimo relativamente alla questione e all'uso di forme sensibili anche in un altro passo dell'introduzione del Tafsìr: «Lo scopo di questo (ovvero della composizione di diagrammi simbolici) è intrattenere l'anima (mu'ānasat al-nafs) per mezzo delle facoltà immaginative sensoriali (al-quwā al-hayāliyya al-hissiyya) e [permettere] la comprensione dei significati intellegibili derivabili da essi (scil. i diagrammi simbolici) per mezzo del senso immaginativo (al-hiss

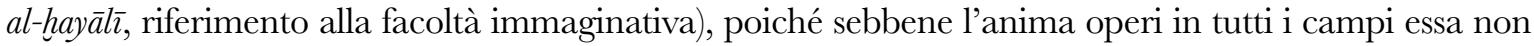
può operare in nessuna cosa afferente agli enti particolari se non attraverso dei mezzi e degli strumenti che essa possiede e dei dieci sensi (5 interni e 5 esterni; ovvero l'anima necessita dei sensi per operare riguardo ai particolari).» Āmulī, Tafsīr al-Muhịt al-a'zam, vol. 5, p. 194, cf. vol. 1, p.103.

30 Āmulī, Tafsìr al-Muhīt al-ązam, vol. 5, pp. 194-195, cf. vol. 1, p. 107. 
L'affinità tra visione in sogno e rappresentazione simbolica costruita ad hoc da un maestro spirituale sembra essere fortissima. Ciò è confermato da molti autori, tra cui Ibn 'Arabī, Būnī, Ḥamūya, Ša 'ranī e lo stesso Āmulī, solo per citare alcuni tra i più importanti, i quali dichiarano che alcuni dei diagrammi da loro inseriti nelle loro opere non sarebbero altro che rappresentazioni di visioni di cui hanno avuto esperienza.

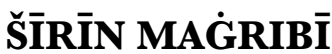

Un altro autore particolarmente importante per la storia delle rappresentazioni grafiche nella letteratura Sufi è ancora un maestro persiano, relativamente poco noto nonostante abbia giocato un ruolo di una certa rilevanza nella trasmissione dell'eredità spirituale di Ibn 'Arabī. Muhammad Šīīn Magribī (m. 810/1408), sebbene sia conosciuto principalmente in qualità di poeta, oltre ad essere uno dei nomi chiave nella trasmissione della Silsila Ḥătimiyya, ovvero il deposito spirituale di Ibn 'Arabī, è al contempo figura assai peculiare per quanto riguarda il fenomeno del Sufismo visivo ${ }^{31}$. La particolarità di Magribī è quella di aver utilizzato diagrammi in tutte le sue opere in prosa che ci sono pervenute, facendo della rappresentazione grafica simbolica la cifra della propria produzione letteraria. La centralità accordata da Mag̉ribī all'elemento visivo non rimarrà senza conseguenze. Essa sarà ripresa dai sui immediati discepoli i quali, a loro volta, utilizzeranno diagrammi nei propri scritti, così come la presenza di diagrammi sarà une delle ragioni principali del successo di una delle sue opere, il Ğäm-i ğahān-namā, ovvero La coppa mostra-mondo ${ }^{32}$. Questo breve trattato, un vero e proprio distillato di metafisica Akbariana espressa in una prosa persiana di rara chiarezza e semplicità, venne copiato, studiato e commentato in tutta l'ecumene persofona dalla Penisola Anatolica all'India ed ebbe un ruolo chiave nel processo di penetrazione e diffusione delle dottrine Akbariane nel Subcontinente Indiano e nello sviluppo dottrinale di varie confraternite, in particolare della Šațāriyya ${ }^{33}$. Nelle opere in prosa di Mag̉ribī sono

31 Sul ruolo di Šìñn Mağribī nella trasmissione di silsile risalenti a Ibn 'Arabī si veda Giovanni Maria Martini, "Muhammad Šìīn Mağribī (d. 810/1408) as a Key Agent in the Transmission of Akbarī Silsilas", Arabica, 68 (2021), pp. 121-170.

32 Ho tentato di contestualizzare l'uso estensivo di diagrammi da parte di Maǵribī e l'influenza intellettuale esercitata da questa scelta sui suoi discepoli diretti e lettori postumi nel già menzionato studio di prossima pubblicazione "Shīrīn Maghribī's (d. 810/1408) Visual Sufism: Diagrams, Intellectual Networks and the Transmission of Spiritual Knowledge in 14th Century Tabriz and beyond".

33 Sul ruolo e l'influenza del Ğām-i ğahān-namā quale veicolo principale dell'eredità intellettuale di Mag̉ribī si veda ancora Martini, "Shīrīn Maghribīs (d. 810/1408) Visual Sufism”. Per una valutazione preliminare sul ruolo svolto da questo testo di Maǵribī nella dottrina e nelle opere dei maestri della Tarīqa Šattāriyya nel Subcontinente Indiano si vedano le interessanti osservazioni di Adithya Behl, Love's Subtle Magic: An Indian Islamic Literary Tradition, 1379-1545, Oxford-New York, Oxford University 
presenti diversi riferimenti all'utilizzo delle immagini ${ }^{34}$. Il brano che segue è tratto da un'opera di cosmologia scritta in Persiano e che per lungo tempo era stata ritenuta perduta ${ }^{35}$. Si tratta di un testo che contiene un considerevole numero di diagrammi, atti a illustrare le varie realtà metafisiche implicate nel processo di manifestazione: dall'Intelletto primo 'scendendo' fino alle sfere celesti e agli elementi costitutivi del mondo sublunare. Nell'introduzione leggiamo:

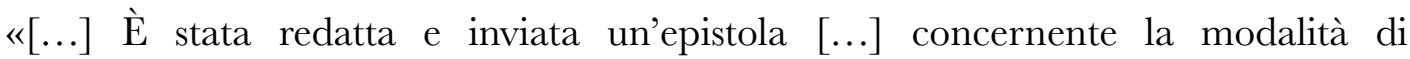
manifestazione e di disposizione dei mondi (kayfiyyat-i zuhūr va tart̄̄b-i 'avālim) e l'apparizione dei loro segni e delle loro forme $(a s k \bar{a} l)$, dal principiare del mondo

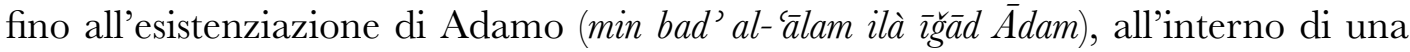
veste fatta di cerchi e di figurazioni (dar kisvat-i davāîr va aškāl) e all'interno di una forma archetipica e immaginale (va dar șürat-i mitāl va hay $\bar{a} l$ ), allo scopo di facilitarne la visualizzazione e favorirne la contemplazione (tashīlan li-tasawrwuri-hā wa-taysīran li-tadabburi-hā). ${ }^{36} \gg$

Grazie ai testi analizzati in precedenza i sintetici riferimenti di Maǵribī risultano subito chiari. Il maestro di Tabriz parlandoci di "una veste fatta di cerchi e di figurazioni” conferma il fatto che ci troviamo difronte a un processo di rivestimento di realtà trascendenti all'interno di rappresentazioni formali; che tali forme, seppure percepibili dai sensi, hanno tuttavia natura intermedia, a cavallo tra manifestazione grossolana e stati sovraformali, essendo «ṣūrat-i mitāl va hayāl», ovvero "forma relativa alla facoltà immaginativa e al mondo degli archetipi". Infine ribadisce che l'utilizzazione di questa modalità espressiva ha come scopo principale quello di facilitare la comprensione di tali realtà trascendenti da parte dei suoi lettori, ovvero i suoi discepoli a Tabriz, per i quali Maǵribī compose questo testo mentre si trovava nella regione del Gilan, presso il Mar Caspio ${ }^{37}$. I medesimi concetti sono espressi da Maǵribī nell'introduzione del sua opera di maggior fortuna, a cui si è accennato pocanzi, il Ğàm-i ğahān-namā:

Press, 2012, pp. 236-240 e passim.

34 Lo scrivente sta curando un'edizione critica delle opere in prosa di Šīīn Mag̉ribī.

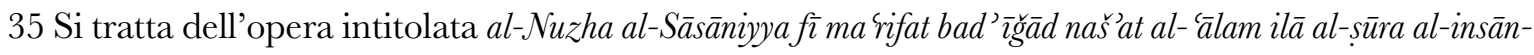
iyya, traducibile come "Il diletto di Sāsān riguardo alla conoscenza del principio dell'esistenziazione del mondo fino alla [creazione della] forma umana", sulla quale si veda il già citato Martini, "alNuzha al-Sāsāniyya by Shīrīn Maghribī (d. 810/1408)".

36 Muhammad Šìrīn Mag̣ribī, al-Nuzha al-Sāsāniyya, Cf. MS Oslo, Schøyen Collection 5350, f. 11 vv. $37 \mathrm{Sul}$ contesto in cui fu redatta e la datazione di quest'opera si veda Martini, “al-Nuzha al-Sāsāniyya by Shīrīn Maghrib̄̄”. 
«Un gruppo di amici che erano alla ricerca della Scienza dell’Unità ( $\left(\text { lm }_{\mathrm{i}} \mathrm{i} \text { tawh } \bar{\imath} d\right)^{38}$ e desideravano intraprendere il passo della realizzazione $(t a h q \bar{\imath} q)$ e del distacco dai fenomeni (tağrid) e che non riuscivano a ottenere la certitudine per mezzo delle parole

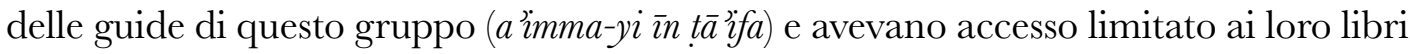
e difficoltà a intendere le loro metafore (va az kutub-i ǐšàn va fahm-i ibāāāt-i ān āqāsir büdand), implorarono questo poveruomo: "Componi un'epistola che raccolga tutti gli

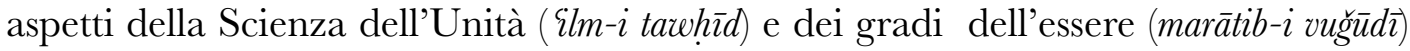
e traccia una circonferenza (dāira) per ogni grado (barā-yi har martaba) e mostra la forma di ogni grado (șürat-i har martaba) sotto forma di una circonferenza (dä $\overrightarrow{i r a}$ ), e per mezzo di chiavi fatte di forme sensibili (bi-mafātz̄ h-i șvar-i mahsūusāt) schiudi i significati e gli intellegibili (ma 'ân̄ va ma'qūlāt)". E io ho risposto alla loro richiesta e dopo aver domandato autorizzazione a Dio mi sono dedicato alla sua redazione e ho chiamato l'epistola La coppa mostra-mondo. ${ }^{39}{ }$ »

Seppure in modo più sintetico rispetto a quanto letto in Āmulī, il meccanismo sotteso alla costruzione delle raffigurazioni simboliche è il medesimo anche per Maǵribī, dal quale viene riassunto poeticamente nella metafora che ci parla dei diagrammi come di "una chiave sensibile che schiude i significati intellegibili". Anche la motivazione per l'impiego del mezzo grafico è chiara. Questa nuova modalità è resa necessaria dalle difficoltà incontrate da alcuni novizi nella comprensione di quei medesimi concetti espressi sotto forma scritta e di metafore letterarie nei testi dei maestri più antichi. Da questo testo di Maǵribī si evince anche un altro aspetto piuttosto interessante relativamente alla storia intellettuale e sociale. Mi riferisco al fatto che siano i discepoli a richiedere espressamente al maestro la redazione di un testo focalizzato sui diagrammi, il quale sembra stare ad indicare che all'epoca e nell'ambiente in cui operava Magribī il Sufismo visivo non fosse un'amenità bensì un apprezzato mezzo di

38 Il temine arabo qui utilizzato da Mag̉ribī è tawhīd. Esso nel linguaggio teologico islamico designa la professione di fede monoteista. Lo stesso termine per i maestri del Sufismo esprime però qualcosa che va aldilà di una semplice proclamazione del Dio uno e unico che partendo dal significato grammaticale del termine implica un processo attivo di trasformazione interiore e di 'verificazione' dell'unità divina. Tawhìd è in effetti l'infinito della forma verbale wahhada che letteralmente significa unificare, fare l'unità, rendere unico, il quale attribuisce alla parola una sfumatura decisamente attiva e dinamica. Per queste stesse ragioni il modo forse più corretto di rendere tawhīd in italiano è dunque "unificazione", ovvero il processo attivo che mira a ricondurre tutto all'Unità. Su tutto questo si vedano le osservazioni di Alberto Ventura in "L«'Epistola dell’Unificazione» di Arslān di Damasco" in Sapienza sufi, Dottrine e simboli dell'esoterismo islamico, Roma, Edizioni mediterranee, 2016, pp. 100-128, da cui sono tratte le considerazioni che precedono.

39 Mağribī, Risāla-yi Ğām-i ğahān-namā, estratto dall'introduzione tradotto sulla base dell'edizione critica preparata dallo scrivente. Cf. l'edizione del testo (la quale contiene tuttavia numerose sviste) in Abū Ṭālib Mīr-'Ābid-

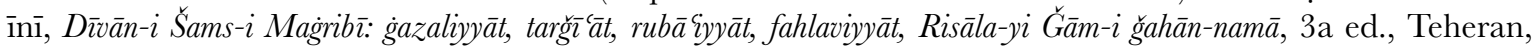
Mu'assasa-yi intišārāt-i Amīr Kabīr, 1393 h.š./2014, p. 248. 
cui la comunità intellettuale era ben conscia, impressione corroborata dal fatto che alcuni discepoli diretti del maestro di Tabriz abbiano composto a loro volta testi corredati da diagrammi simbolici ${ }^{40}$.

\section{LA TPARĪQA NAQŠBANDIYYA}

Tra le confraternite che come e più di altre hanno recepito nei secoli e utilizzato raffigurazioni simboliche tra le loro tecniche di realizzazione iniziatica, e che continuano a utilizzarle in epoca contemporanea, si annovera la Tariqa Naqšbandiyya ${ }^{41}$. Un caso esemplare in questo senso è rappresentato dal maestro naqšbandī del ventesimo secolo Abū l-Hasan Zayd Fārūqī (m. 1993) che include numerosi diagrammi nella sua opera persiana intitolata Manāhiğ al-sayr va madārğ al-h̆ayr; diagrammi che sono stati studiati e commentati da Alberto Ventura nel suo recente saggio Lo yoga dell'Islam ${ }^{42}$.

40 Su questo aspetto si veda Martini, "Shīrīn Maghribī’s (d. 810/1408) Visual Sufism”.

41 Per alcuni esempi e analisi di raffigurazioni diagrammatiche in testi Naqšbandī si vedano Marcia K. Hermansen, "Shāh Walī Allāh's Theory of the Subtle Spiritual Centres (Lațāifi): A Sufi Model of Personhood and Self-Transformation", Fournal of Near Eastern Studies, 47, No. 1 (1988), pp. 1-25; idem., "Mystical Paths and Authoritative Knowledge: A Semiotic Approach to Sufi Cosmological Diagrams", Fournal of Religious Studies and Theology, 12 (1992), pp. 52-77; Demetrio Giordani, "Stages of Naqšbandī sulūk in Šāh Abū Sa'īd Muğaddidī’s Hidāyat al-Ṭālibīn”, Oriente Moderno, 92 (2012), pp. 393-417. Si veda anche Samuela Pagani, Il rinnovamento mistico dell'Islam, un commentario di Abd alĠañ al-Nābulusī a Ahmad Sirhind̄̄, Napoli, Università degli studi di Napoli "L'Orientale"-Il Torcoliere, 2003, pp. 230-232.

42 Abū l-Hasan Zayd Fārūqī, Manāhiğ al-sayr va madārğ al-hayr, Qandahar, 'Abd al-Ġaffār va pisarān, 1957; traduzione urdu in Abū l-Ḥasan Zayd Fārūqī, Manāhiğ al-sayr va madārğ al-hayr, Mawlānā Muhammad Na`īm Allāh Ḩayālī Șāḥib (trad.), Guğrāt (Pakistan), Muhammad Fayyāḍ Ṣadīqī Muğaddidī (stampatore), 1434/2013; traduzione inglese in Hazrat Abu al-Hasan Zaid Faruqi Mujaddidi Dehlavi, Pathways of Mystic Fourney and Avenues of Beatitude (Minhaj al-sayr wa madarij al-khair), Sardar Ali Ahmad khan (trad.), Sheikhopura (Pakistan), Sahibzada Mian Jamil Ahmad Sharaqpuri (stampatore) presso Darul Muballigheen Hazrat Mian Sahib, Sharaqpur Sharif, , s.d. (probabilmente 1413/1992). Un esempio delle numerose problematiche relative alla trasmissione degli elementi grafici che costituiscono il corpus del Sufismo visivo, sia nella tradizione manoscritta dei testi, sia nelle edizioni a stampa moderne è nella succitata traduzione inglese, in cui è presente uno solo dei diciannove diagrammi contenuti nel testo originale. Il testo di Fārūqī è una delle fonti principali del saggio di Alberto Ventura, Lo yoga dell'Islam, Roma, Edizioni Mediterranee, 2019. Sui diagrammi si vedano in particolare i cap. VI. "Dottrina e metodo dei centri sottili" e VIII. "Le contemplazioni". 


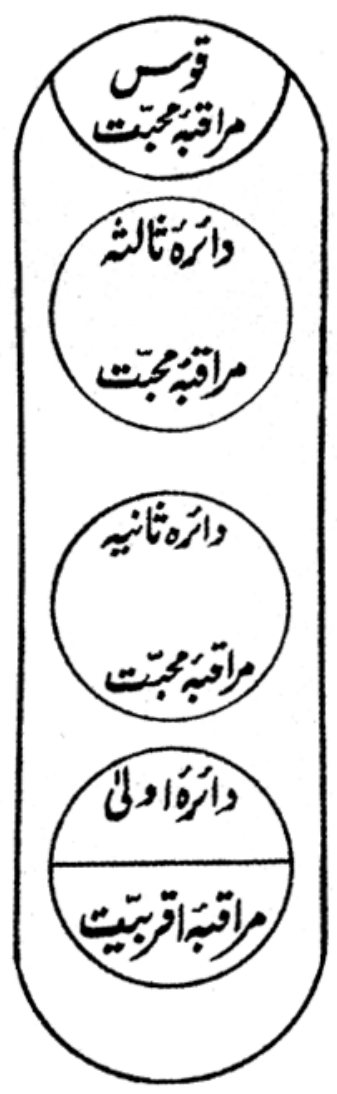

Fïgura 6: Fārūqī, Manāhiğ al-sayr, "Cerchio della santità maggiore” (Dāirra-ya valāyat-i kubrā $)^{43}$.

Tali figure, il cui carattere 'operativo', oltre che esplicativo, è stato messo chiaramente in evidenza da Ventura ${ }^{44}$, costituiscono un elemento centrale nel trattato di Fārūqī poiché rappresentano i sette sentieri (madāriğ) menzionati nel titolo dell'opera, ovvero sette stazioni principali nel cammino iniziatico, corrispondenti ad altrettanti 'stati dell'esistenza' che l'iniziato è chiamato ad attraversare (ovvero a reintegrare) proprio grazie anche alla meditazione sui diagrammi ${ }^{45}$. Le raffigurazioni contenute nei Manāhiğ al-sayr nella maggior parte dei casi sono semplici circonferenze contenenti del testo inscritto al loro interno e l'uso

43 Dal basso verso l'alto: dā ira-yi avval, murāqaba-yi aqrabiyyat ("primo cerchio, contemplazione della maggior vicinanza"); dā îra-yi țāniyah, murāqaba-yi mahabbat ("secondo cerchio, contemplazione dell'amore"); dā îra-yi tālitah, murāqaba-yi mahabbat ("terzo cerchio, contemplazione dell'amore"); qaws-i murāqaba-yi mahabbat ("arco della contemplazione dell'amore"); Per un'analisi di questo diagramma si veda Ventura, Lo yoga dell'Islam, pp. 104-105.

44 Ventura, Lo yoga dell'Islam, in particolare i cap. VI. "Dottrina e metodo dei centri sottili" e VIII. "Le contemplazioni".

$45 \mathrm{Su}$ tutto questo si veda ancora Ventura, Lo yoga dell'Islam, p. 99 e seguenti. 
di questa particolare forma geometrica per rappresentare simbolicamente le stazioni del cammino spirituale è spiegata da Farūqī con le seguenti parole:

«Le stazioni che portano alla prossimità con il divino vengono descritte come cerchi (dawāir perché queste forme circolari sono vuote, prive di lati o direzioni, non hanno né sopra né sotto, né destra né sinistra, né inizio né fine; e questo - ha detto Shāh Ghulām 'Alī - fino a dove c’è Dio, perché lì quale cerchio potrebbe mai esservi? ${ }^{46}{ }$ ”

\section{GONGLUSIONI}

Alla domanda iniziale, ovvero se i diagrammi e le raffigurazioni disseminate nella letteratura Sufi siano stati ideati per essere degli strumenti di realizzazione iniziatica, sulla base dei testi esaminati è ragionevole dare una risposta affermativa: essi furono concepiti a tutti gli effetti dai loro autori e utilizzati dai loro lettori come strumenti operativi a supporto della realizzazione spirituale, sia per facilitare la comprensione teorica preliminare di concetti metafisici astratti, sia dal punto di vista operativo in qualità di supporti rituali alla meditazione. E tuttavia, seppure possiamo affermare che $\mathrm{i}$ testi ci restituiscono una risposta positiva a questa domanda, tale risposta rimane, almeno sotto certi aspetti, incompleta. Se infatti gli autori sono relativamente prodighi di informazioni riguardo agli aspetti teorici, alla natura di queste rappresentazioni e alle ragioni che li condussero a sviluppare questo particolare mezzo espressivo, essi il più delle volte forniscono solamente sporadici dettagli in merito agli aspetti pratici riguardanti l'uso operativo di queste immagini ${ }^{47}$. A questo proposito l'impressione è che il silenzio generalizzato delle fonti scritte riguardo agli aspetti operativi non sia affatto casuale. Così come avviene in linea generale e con le dovute eccezioni per tutte le tecniche e i riti del Sufismo (si pensi ai riti di iniziazione e alla trasmissione e recitazione degli adkār) il silenzio delle fonti scritte pare suggerire che l'impartizione delle istruzioni pratiche su come andasse condotta la meditazione di tali raffigurazioni fosse riservata alla trasmissione orale diretta da maestro a discepolo. Tale modus cogendi et operandi in effetti sembra essere indirettamente confermato da alcuni degli autori citati. A questo proposito è utile citare un passo tratto da un'altra opera inedita di Šìīn Mag̉ribī, di cui sto curando l'edizione critica, anch'essa corredata di diagrammi, in cui il maestro di Tabriz afferma esplicitamente

46 Fārūqī, Manāhiğ al-sayr, p. 60, traduzione di Alberto Ventura in Lo yoga dell'Islam, p. 100.

47 Nonostante le difficoltà testé menzionate, dall'esame di un esteso corpus di opere è comunque possibile ricavare alcuni dati sugli aspetti più prettamente operativi del Sufismo visivo, tra cui l'uso di termini tecnici ricorrenti per fare riferimento alla meditazione sui medesimi. Come già ricordato, alcune significative considerazioni sull'uso operativo dei diagrammi contenuti nell'opera di Fārūqī si trovano nello studio di Ventura, Lo yoga dell'Islam, p. 99 e seguenti. 
l'esistenza di molteplici livelli di conoscenza e trasmissione della scienza iniziatica di cui la comunicazione scritta rappresenterebbe solo la modalità più esteriore:

«Il maestro realizzato ${ }^{48}$ sa che non si deve dire tutto ciò che si sa e che non si deve scrivere tutto ciò che si dice, ché il locutore dirà secondo la capacità dell'interlocutore, mentre lo scritto sarà visto e sarà letto dal superiore e dall'inferiore, da chi è vicino e da chi è lontano e da chi è capace e da chi è incapace, cosicché è possibile che qualcuno comprenda e qualcuno non comprenda; e che qualcun altro ancora mal comprenda; e che questi ultimi si formino un'idea sbagliata; e che quest'ultima li danneggi e certuni agiscano contrariamente alla legge divina perché della legge divina hanno poca dimestichezza e per questa [stessa] ragione si facciano una cattiva opinione dell'autore. ${ }^{49}{ }^{\prime}$

48 Il termine impiegato da Maġribī è muhaqqiq, largamente utilizzato nel linguaggio tecnico del Sufismo. Letteralmente il muhaqqiq è colui che verifica e invera $(t a h q \bar{\imath} q)$ la Verità (al-haqq) ovvero realizza la Realtà (ancora al-haqq); due termini, Verità e Realtà, che in questo contesto rimandano a ciò che nel linguaggio teologico chiamiamo 'Dio'. Una caratteristica interessante del termine arabo muhaqq$i q$, che si perde nella traduzione italiana "realizzato", è quella di non essere un participio passato (il quale rimanda, almeno implicitamente, a un evento avvento nel passato) bensì un nome d'agente, che indica che l'azione in questione è in atto qui e ora e in modo continuativo, ovvero che l'iniziato pervenuto al grado spirituale di muhaqqiq verifica e invera la Verità e realizza la Realtà senza soluzione di continuità.

49 Šīīn Mağribī, al-Durr al-farìd fì ma rifat marātib al-tawhīd, traduzione basata sull'edizione critica, attualmente inedita, dello scrivente. Per un riferimento testuale rimando al più antico manoscritto da me utilizzato in sede di collazione: MS Istanbul, Süleymaniye Kütüphanesi, Şehid Ali Paşa 1373, datato 845 (1442), f. 33r-v. Sul carattere di riservatezza della trasmissione, anche in forma scritta, di tesi e nozioni dottrinali negli ambienti del Sufismo, si leggano le interessanti considerazioni di Noah Gardiner, "Esotericist Reading Communities and the Early Circulation of the Sufi Occultist Ahmad al-Būnī's Works", Arabica, 64 (2017), pp. 405-441, specialmente 415 e seg. Cf. un passo pregnante di Ibn 'Arabī che recita: "Il limite a cui ci arrestiamo nei nostri libri è di indirizzarci solo ai nostri compagni (ashābunā) in modo tale che nessuno ad eccezione di loro possa capire ciò a cui alludiamo e in modo tale che nessuno ad eccezione di loro possa ottenerlo", Ibn 'Arabī, Le livre du mim, du waw et du nun [Kitāb al-Mīm wa-l-wāw wa-l-nūn], Charles Gilis (ed. e trad.), Beirut, Editions Albouraq 2002, p. 58 (cit. anche da Gardiner, "Esotericist Reading Communities", p. 491). Nel contesto islamico premoderno una separazione netta tra trasmissione orale e scritta era del resto quasi del tutto inesistente anche per quanto riguarda le scienze essoteriche, dato che in linea generale e tralasciando le eccezioni, che pur esistono, i testi (Corano in primis, ma analogamente ogni altro testo afferente alle più varie discipline) venivano letti, studiati, commentati e finalmente ricopiati al cospetto di un maestro qualificato e nient'affatto in solitudine, come tendiamo invece a concepire (e dunque a esercitare) la lettura in epoca contemporanea. È questo un aspetto sufficientemente noto e che tuttavia merita di essere continuamente sottolineato in quanto la percezione di autosufficienza della testo e della trasmissione scritta è così fortemente radicata nella mentalità moderna da spingerci ad applicare questi stessi parametri retrospettivamente a un contesto culturale profondamente diverso, in cui i testi erano 
Come abbiamo avuto modo di intravvedere, il fenomeno del Sufismo visivo ha continuato a svilupparsi ininterrottamente fino all'epoca moderna e ogni secolo e ogni area geografica del mondo musulmano hanno dato i natali a maestri che di volta in volta hanno scelto di utilizzare questo particolare mezzo espressivo visivo e in alcuni casi è persino possibile rintracciare una continuità sia contenutistico-dottrinale, sia figurativa, tra le raffigurazioni tracciate da maestri vissuti in epoche e regioni molto distanti tra loro, a dimostrazione che quasi mai le elaborazioni di questi autori furono l'invenzione di singole individualità che agivano in modo isolato, bensì l'esito, di volta in volta unico e irripetibile, di una tradizione spirituale vivente e di una fitta trama culturale ${ }^{50}$.

Nelle pagine che hanno preceduto è stata presa in esame una selezione di fonti primarie relative a epoche e contesti geografici assai diversi, dalla cui analisi è possibile ricavare una prima impressione generale sul quel peculiare fenomeno che ho denominato 'Sufismo visivo' e sulle implicazioni di quest'ultimo dal punto di vista della storia delle idee nel mondo musulmano. E tuttavia si tratta di necessità, come ricordato fin dalle prime righe, di uno studio circonstanziato dedicato a un aspetto specifico, ovvero a come le raffigurazioni qui oggetto di studio possano e debbano essere intese in qualità di strumenti tecnici per la realizzazione spirituale nel Sufismo. È qui mancato ogni accenno ad altrettanti aspetti fondamentali della questione, tra cui le origini di questo fenomeno; i suoi rapporti con materiali grafici presenti in testi di altre discipline, anche di epoca antecedente, in ambito islamico; al perché tale mezzo sembrerebbe essersi affermato in ambito sufi solo a partire da un certo periodo; e alle possibili analogie con materiali simili presenti in altre tradizioni spirituali sia orientali che occidentali. Questi solo per citarne alcuni, a cui va aggiunta la considerazione di carattere generale relativa al fatto che manca a tutt'oggi un catalogo esaustivo di tutti i materiali grafici che ricadono nell'ambito stesso di questa indagine, ovvero che non è a tutt'oggi accessibile allo studioso, nella sua interezza, la materia prima stessa della ricerca. Il lavoro da intraprendere per gettar luce su questo peculiare aspetto della storia del Sufismo è ancora lungo. La speranza di chi scrive è che le considerazioni che hanno preceduto possano servire a stimolare la riflessione sull'argomento.

invece concepiti principalmente come supporti e aiuti in un processo di trasmissione della conoscenza basato essenzialmente sull'oralità, dunque sul rapporto diretto tra due (o più) individui e non interamente mediato (ovvero 'interrotto' da un certo punto di vista) dal testo. Non è forse esagerato suggerire che tale profondo mutamento di paradigma in relazione al ruolo della scrittura rappresenti una delle differenze salienti tra mentalità premoderna e moderna.

$50 \mathrm{Su}$ un caso di trasmissione, riaffiorare e rielaborazione di un determinato diagramma nei secoli e in aree geografiche diverse, si rimanda all'esempio discusso in Martini, "Shīrīn Maghribī’s (d. 810/1408) Visual Sufism". 


\section{RIFERIMENTI BIBLIOGRAFIGI}

ALEXANDRIN, Elizabeth R. (2012), "Witnessing the Lights of the Heavenly Dominion Dreams, Visions and the Mystical Exegeses of Shams al-Dīn al-Daylamī”, in Dreams and Visions in Islamic Societies, Özgen Felek e Alexander D. Knysh (ed.), Albany, State University of New York Press, pp. 215-31.

ALEXANDRIN, Elizabeth R. (2018), "Secret Alphabets and Sealed Texts in Three Unedited Works of Sa'd al-Dīn Hamūyeh", comunicazione orale durante il workshop "Visualizing Sufism" presso lo Alexander von Humboldt Kolleg for Islamicate Intellecual History, Università di Bonn, 14 maggio 2018.

ĀMULĪ, Haydar (1975), al-Muqaddimāt min Kitāb Nașs al-nușūs fĩ šarh Fusūs al-hikam li-Muhȳ al-Dīn Ibn al-'Arabī/Le texte des textes (NASS AL-NOSUS), commentaire des "Fosûs al-hikam» d'Ibn 'Arabî, Les prolégomènes, Henry Corbin e Osman Yahya (ed.), Teheran-Parigi, Département d'iranologie de l'Institut Franco-Iranien de recherche-Librairie d'Amérique et d'Orient Adrien-Maisonneuve.

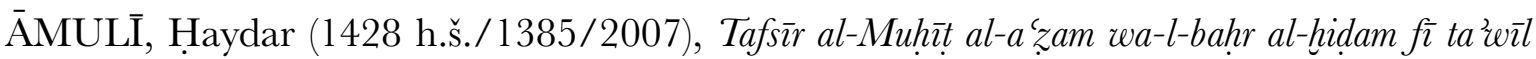
kitāb Allāh al-'azīz al-muhkam, 6 voll., al-Sayyid Muḥsin al-Mūsawī al-Tabrīzī (ed.), Qom, Mu’assasa-yi farhangī va našr-i nūr 'alā nūr.

ARBERRY, A. J. (1966), "The Works of Shams al-Dīn al-Dailamī”, Bulletin of the School of Oriental and African Studies, University of London, 29 No. 1, pp. 49-56.

BEHL, Adithya (2012), Love's Subtle Magic: An Indian Islamic Literary Tradition, 1379-1545, Oxford-New York, Oxford University Press.

BÖWERING, Gerhard (1987), "The Writings of Shams al-Dīn al-Daylamī”, Islamic Studies, 26, No. 3, pp. 231-236.

BUSI, Giulio (2005), Qabbalah visiva, Torino, Einaudi.

AL-HALLĀJ, al-Ḥusayn Ibn Manșūr (2007), Il cristo dell'Islam. Scritti mistici, a cura di Alberto Ventura, Milano, Arnoldo Mondadori Editore.

CANTEINS, Jean (1981), La voie des lettres, tradition cachée en Israël et en Islam, Parigi, Albin Michel.

DE JONG, Frederick (1989), "The iconography of Bektashiism. A survey of themes and symbolism in clerical costume, liturgical objects and pictorial art", Manuscripts of the Midle East 4, pp. 7-29.

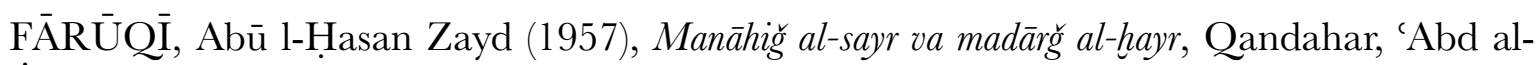
Ġaffār va pisarān,

FĀRŪQ̄̄, Abū l-Hasan Zayd (1434/2013), Manāhiğ al-sayr va madārğ al-hayr, Mawlānā Muḥammad Na'īm Allāh Huayālī Șāḥib (trad.), Guğrāt (Pakistan), Muḥammad Fayyāọ Ṣadīqī Muğaddidī (stampatore). 
[FĀRŪQ̄̄, Abū l-Hasan Zayd], Hazrat Abu al-Hasan Zaid Faruqi Mujaddidi Dehlavi (s.d., prob. 1413/1992), Pathways of Mystic Fourney and Avenues of Beatitude (Minhaj al-sayr wa madarij alkhair), Sardar Ali Ahmad khan (trad.), Sheikhopura (Pakistan), Sahibzada Mian Jamil Ahmad Sharaqpuri (stampatore) presso Darul Muballigheen Hazrat Mian Sahib, Sharaqpur Sharif.

GARDINER, Noah (2017), "Esotericist Reading Communities and the Early Circulation of the Sufi Occultist Aḥmad al-Būnīs Works", Arabica, 64 (2017), pp. 405-441.

GARDINER, Noah (2018), "Diagrams as Keys to the Kingdom in Ahmad al-Būnīs Latā if al-ishārāt fì al-hurūf al-ulwēyāt", comunicazione orale durante il workshop "Visualizing Sufism" presso lo Alexander von Humboldt Kolleg for Islamicate Intellecual History, Università di Bonn, 14 maggio 2018.

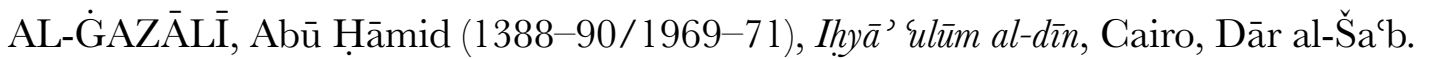

GIORDANI, Demetrio (2012), "Stages of Naqšbandī sulūk in Šāh Abū Sa '̄̄d Muğaddidī’s Hidāyat al-Tălibìn", Oriente Moderno, 92, pp. 393-417.

[AL-ǦURǦGĀNī, 'Alī b. Muhammad] 'Alī b. Muhammad al-Jurjānī (1994), Kitāb al-Ta'rñfāt, Maurice Gloton (trad. e ed.), Pierre Lory (pref.), Teheran, Presses Universitaieres d'Iran.

HERMANSEN, Marcia K. (1988), "Shāh Walī Allāh's Theory of the Subtle Spiritual Centres (Lațāif): A Sufi Model of Personhood and Self-Transformation", fournal of Near Eastern Studies, 47, No. 1, pp. 1-25; i

HERMANSEN, Marcia K. (1992), "Mystical Paths and Authoritative Knowledge: A Semiotic Approach to Sufi Cosmological Diagrams", fournal of Religious Studies and Theology, 12, pp. 52-77.

KARAMUSTAFA, Ahmet T. (1992), "Cosmographical Diagrams", in The History of Cartography, Volume 2, Book 1: Cartography in the Traditional Islamic and South Asian Societies, J. B. Harley e David Woodward (ed.), Chicago-Londra, The University of Chicago Press, pp. 71-89.

KNYSH, Alexander D. (2006), "Șūfism and the Qur'ān", in Encyclopaedia of the Qur'ann, Jane Dammen McAuliffe (ed.), Leida-Boston, Brill, vol. 5, pp. 137-159.

[IBN 'ARAB̄̄] Ibn 'Arabî (1996), La production des cercles, Paul Fenton e Maurice Gloton (ed. e trad.), Parigi, Édition de l'Éclat.

IBN 'ARABĪ (2002), Le livre du mim, du waw et du nun, Gharles Gilis (ed. e trad.), Beirut, Editions Albouraq.

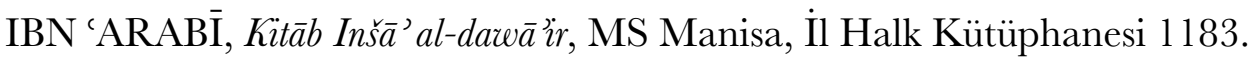

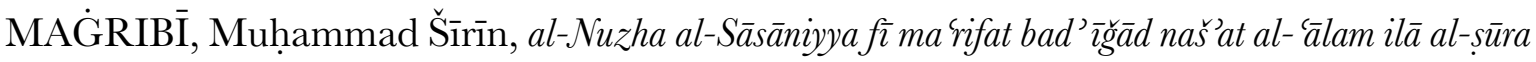
al-insāniyya, MS Oslo, Schøyen Collection 5350, ff. $116 \mathrm{r}-143 \mathrm{v}$.

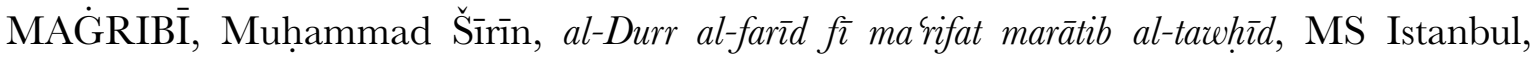
Süleymaniye Kütüphanesi, Şehid Ali Paşa 1373. 
MARCONI, Maurizio (2018), "Il libro della produzione dei cerchi di Ibn 'Arabī”, El Azufre Rojo, 5, pp. 33-102.

MARTINI, Giovanni Maria (2021), “al-Nuzha al-Sāsāniyya by Shīrinn Maghribī (d. 810/1408): A Recently-Discovered Cosmological Treatise in Persian of the School of Ibn al-'Arabī", Oriens, 49 (2021), pp. 35-94.

MARTINI, Giovanni Maria (2021), "Muhammad Šīīn Magiribī (d. 810/1408) as a Key Agent in the Transmission of Akbarì Silsilas", Arabica, 68, pp. 121-170.

MARTINI, Giovanni Maria (di prossima pubblicazione), "Shīīn Maghribī's (d. 810/1408) Visual Sufism: Diagrams, Intellectual Networks and the Transmission of Spiritual Knowledge in 14th Century Tabriz and beyond".

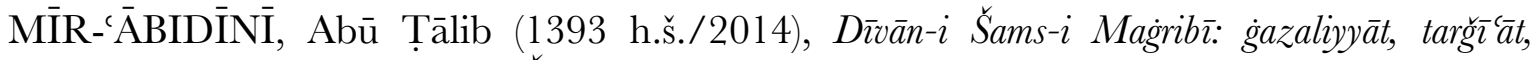
rubāîyyāt, fahlaviyyāt, Risāla-yi Ğām-i ğahān-namā, 3a ed., Teheran, Mu'assasa-yi intišārāt-i Amìr Kabīr, p. 248.

NYBERG, H. S. (1919), Kleinere Schriften des Ibn 'Arabī, nach Handschriften in Upsala und Berlin zum ersten Mal herausgegeben und mit Einteitung und Kommentar versehen, Leida, E.J. Brill.

NWYIA, Paul (1972), "Hallāğg. Kitāb al-Ṭawāsīn. Édition nouvelle", Mélanges de l'Université Saint Joseph 47, pp. 183-238.

PAGANI, Samuela, Il rinnovamento mistico dell'Islam, un commentario di Ábd al-Ġañ al-Nābulusī a Ạmad Sirhindī, Napoli, Università degli studi di Napoli "L’Orientale"-Il Torcoliere.

SPEZIALE, Fabrizio (2007), "Il simbolismo mistico del volto umano nel trattato (in urdu) Sūrat-i ma qūma-yi șuwari Silm di Karīm Allāh 'Āshiq", Journal Asiatique 295.2, pp. 439-59.

TASBIHI, Eliza (2018), "Esoteric Deliberations on Visionary Unveiling: Mystical Knowledge From Haydar Āmulī’s (d. 1385) Nașs al-nusūss fì sharh al-Fusūs al-Hikam”, comunicazione orale durante il workshop "Visualizing Sufism" presso lo Alexander von Humboldt Kolleg for Islamicate Intellecual History, Università di Bonn, 14 maggio 2018.

TASBIHI, Eliza (2021), "Visionary Perceptions through Cosmographical Diagrams: Mystical Knowledge from Ḥaydar Āmulī’s Nass al-nusüs fî sharh Fusūs al-hikam”, JMIAS, 69, pp. 31-81.

TOTTOLI, Roberto (2021), Leggere e studiare il Corano, una guida, Roma, Istituto per l'Oriente G.A. Nallino.

VENTURA, Alberto (2016), Sapienza sufi, Dottrine e simboli dell'esoterismo islamico, Roma, Edizioni mediterranee.

VENTURA, Alberto (2019), Lo yoga dell'Islam, Roma, Edizioni Mediterranee. 